\title{
Post-merger and Acquisition Integration: A Case Review of Dial Henkel And BP Amoco
}

\author{
Lufina Mahadewi ${ }^{1^{*}}$ \\ ${ }^{1}$ Ppm School of Management, DKI Jakarta 10340, Indonesia
}

\begin{abstract}
A B S T R A C T
Post-merger and Acquisition (M\&A) integration often deals with significant transformational changes of merging companies in terms of development, communication, implementation and harmonization of a new shared vision, strategic objective, corporate culture, and also combination of best companies' value practices. The transformational change is accentuated on facilitating the role of developing and executing an effective post-M\&A Integration to build change cohesively with the strategic management of M\&A, and also in terms of removing barriers to the success of M\&A transaction. The aims of this study are to give a clear and deep understanding on how to manage the soft factors issues that address in M\&A process especially in the post-M\&A integration process and also to elucidate the critical success factor of M\&A process by instilling the best characteristics and the effectiveness level of leadership aspect in M\&A. The methodology used in this research is descriptive qualitative research with a method or approach of a case study of Henkel's Acquisition of The Dial Corporation in 2004. The acquisition of a USA company Dial by a German company Henkel evidenced that both companies were successful in M\&A transaction and employed the effectiveness of multi-culture integration strategy. Another case study used in this research is British Petroleum (BP) and American Oil Company (Amoco) (also Atlantic Richfield Company (ARCO) and Burmah Castrol) in 1998-2000. The case of BP Amoco showed that the monoculture integration strategy or cultural imposition can also lead to a value creation. Both case studies showed that successful integration requires leadership as a foundation to build a solid execution of post-M\&A integration projects in how they planned, communicated and delivered the objectives of the projects.
\end{abstract}

ART I CLE INF O

Merger and Acquisition, Post M\&A Integration, Organizational Culture, Change Management.
*Correspondent Email:

LMD@ppm-management.ac.id 


\section{INTRODUCTION}

The word merger refers to "negotiations between friendly parties, who arrive at a mutually agreeable decision to combine their companies" (Weston \& Weaver, 2001). A merger is the combination of two companies in a stock-for-stock transaction, while an acquisition is the purchase of the stock or assets of a business using the stock of acquirer, cash or other securities (Hunt, 2004). The terms of M\&A with broad Anglo-American sense relates with purchase and sale understanding; concentration between undertakings; alliances, cooperation and joint ventures; formation of companies; Management Buy-In (MBI) and Management Buy-Out (MBO); going public/Initial Public Offering (IPO); change of legal form; and restructuring (Picot, 2002).

The term merger and acquisition can be seen in the same context, where the acquisition is also done with the stock-for-stock transaction. The merger is related to the combination of companies which agrees to form a new single company rather than being remained separately, and acquisition is mostly related to the purchasing of one major company to a smaller company. But, the terms themselves in practice are not contextually different and mutually exclusive, generally merger happens when one major company purchase another company which is technically an acquisition term, but the purchase deal itself is done in a friendly environment where the main goal is to achieve the best interest within the merging companies with mutual agreement to form a new corporation. However, when the purchase deal happens in unfriendly or hostile ways, then it generally refers to the acquisition term. Although the acquisition can also happen in a friendly or hostile deal. The main difference between merger and acquisition resides on the ways of how the deal has been done and the stakeholders' reception of the purchase deal.

To have successful post-M\&A integration, there are several factors that should be managed regarding the soft factors issues; the merged companies have to create a new vision with new shared values, manage the retention problem, create an effective communication strategy, and create functional capabilities with an effective organizational structure. To help in building those concerns effectively, the author suggests the use of a due diligence process as a systemic screening and a strategic evaluation of short-term and long-term synergy value potential partner. As part of comprehensive due diligence, HR due to diligence should be also regarded important as a starting phase to address the soft factors issues of potential merging companies such as sketching out the strength and openness level of the partner's culture. The HR due diligence can also be used to evaluate the readiness and compatibility level of potential management partner.

Successful post-M\&A integration relates to a workable change process that encourages leadership to institute the significant organizational change. The author considers the use of a planned change process based on figure 2 as steps which incorporate leadership with postM\&A integration process and manage the detailed issues inside that process. In one detailed of planned change process which is managing the transition process, the author marks this phase as a crucial phase because in this phase the major transformation process is being executed and involves all elements of companies. In the transition phase, a multi-step process, which can overwhelm all soft factors issues during postM\&A integration, has to be implemented.

The author proposes a model of exemplary leadership from James M. Kouzes to manage the transition process and act as a workable change management plan for post-M\&A integration. The main consideration is that the model is a fully comprehensive approach of leadership practices such as challenging the process, inspiring a shared vision, enabling others to act, modeling the way, and encouraging the hearts which cover all important aspects needed in coping with $M \& A$ change.

\section{LITERATURE REVIEW}

\section{McKinsey 7S Model}

The soft factors are drawn in the "soft S" in the McKinsey 7S Model. The lack of intention in 
managing the soft factors of shared values, style, skills, and staff will result in failure of M\&A change processes.

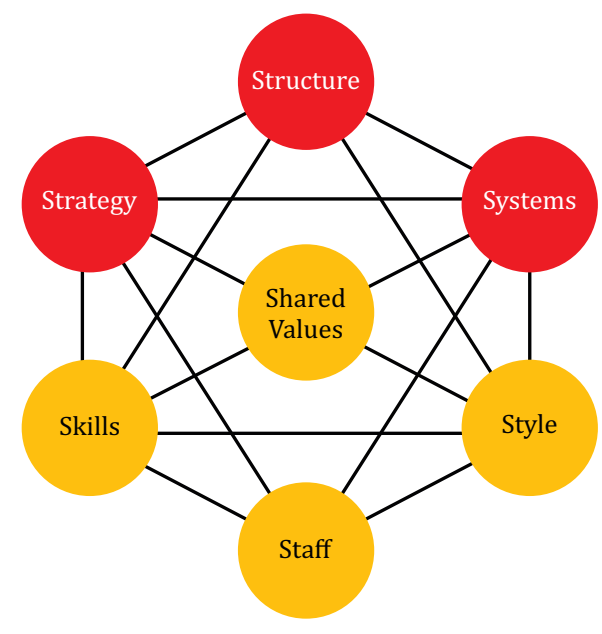

Source: M. Rasiel and Paul N. Friga (2002)

Figure 1. McKinsey 7S Model

The soft factors are a major concern in M\&A change based on empirical evidence of recent M\&A transactions with some issues of clarity of new shared values, employees' communication, key retention, knowledge transfer, and alignment of culture. In cross-border M\&A, the issues of the discrepancy of soft factors mostly take a major attention during post-M\&A integration.

These seven factors of McKinsey can be divided into hard factors and soft factors, in which seven of them correlate each other. The hard factors consist of Strategy as the direction and scope of the company, Structure as the basic organization of the company, its departments, reporting lines, area of expertise, and responsibility (and how they inter-relate), and Systems as formal and informal procedure that govern everyday activity, covering everything from management information systems, through to the systems at the point of contact with the customer, and The soft factors consist of Skills as the capabilities and competencies that exists within the company, Shared values as the values and beliefs of the company, Staff as the company's people resources and how they are developed, trained, and motivated, and Style as the leadership approach of the top management and the company's overall operating approach (Waterman Jr etal., 1988).
To achieve the success of M\&A overall process, an efficient management and integration of hard factors and soft factors of 7s McKinsey factors are becoming the key success factors for managing the overall M\&A process. All the 7 factors should be correlated and managed to realize the synergistic benefit of M\&A.

In this article, the author focuses on managing the soft factors in terms of achieving the successful M\&A process by instilling leadership practices in overcoming the soft issues problems which remain as the toughest issues in M\&A integration process. Strong leadership in managing soft factor issues will give a great leverage in making quick and effective fundamental decisions regarding the human side problems with the intention to cater to the characteristic of successful mergers. Those are being focused in order to be integrated with the hard factors of company's strategic and organizational structure of M\&A transaction towards to achieve the objectives of M\&A transaction.

\section{Organizational Change}

In traditional management, the effectiveness organization is being measured by the degree of stability and orderliness; the managers tend to neglect emotional factors from their work. But now, organizations have become less stable and predictable and leader should have the ability to adjust to the dynamic and changing environment. Leaders have to see the advantages of the change rather than being threatened.

Change is "the coping process of moving a present state to a more desired state in response to dynamic internal and external factors" (Hunsaker, 2005). As described above the strong culture can be a potential resistance of change; below are some resistances of change based on human nature and others which are created from organizational dynamics which consists of selective perception, lack of information, fear of the unknown, habit, resentment towards the initiator, sub-optimization, and structural stability. Those resistances become major roadblocks in M\&A change process because one company perceives other as an external 
disruption. Some experience resistances are being caused by a fear of being dominated by other company, lost the job and responsibility, reduced salary and compensation, personal conflicts and malignity among employees, and so forth.

In the rapid economic of change, forming alliances or consolidation such as merger and acquisition are considered as a strategy against the competition. M\&A related to the integrating the entity of existing companies with changes that have to be managed proactively. To manage the planned M\&A change, these steps below are required in planning and implementing M\&A change in order to avoid the pitfall of the transaction and cope with obstacles generally arise from soft factors issues during the integration process.

The author considers the use of a workable change management plan based on figure 2 below with its detailed explanation of relation steps which incorporated post-M\&A integration planning and executing phase.

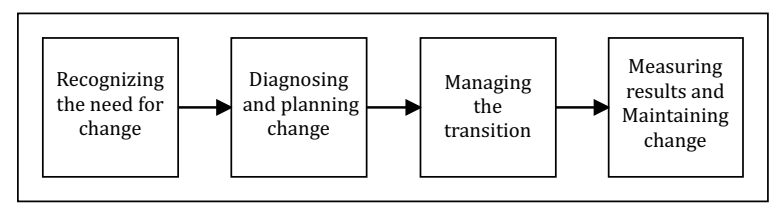

Source: Phillip L. Hunsaker (2005)

Figure 2. Managing the Planned Change Process

The first step is recognizing the need for change in merger integration for every employee from merging companies; the leader should promote the benefit and the necessity of change to every employee where this change affects many key areas of the organizational structure of knowledge, skills, technology, customers, regulators, competitors, and suppliers.

The second step is diagnosing and planning change; the leaders should make specific, detailed plans about implanting desired cultural factors and management practices, eliminating the discrepancy in soft factors issues, capturing combination best practices within merging companies, and finding opportunistic benefit around the shared culture; and leaders should also give clarity to the employees regarding the post $M \& A$ change. Leaders should formulate and measure the gaps of current conditions to a newly combined state of merging companies, and they should consider the effect of change of several domains forces such as the board of directors, staff and employees, volunteers in the organizations, suppliers, and customers. The force field analysis can be used as a consideration to promote change which is defined as the process of analyzing the forces that drives change and the forces that restrain it (Harvey \& Brown, 2000).

The third step is managing the transition; the author focuses on this process as the main concern of the change's step process. Here, the author gives a detailed explanation of how to manage the transition process before the fourth step of managing the planned change which is measuring results and maintaining change is going to be described. The considerations of the focus are: leaders should be aware of the disruptive effect of M\&A changes and able to manage the negative influence during the transition process. Inappropriate in managing transition process can result in diminishing potential benefits and value creation expected from M\&A. During the transition process, leaders should also be able to give appropriate support and facilitate a condition that helps to minimize fear, uncertainty, and doubt; enables employees to focus, and builds positive employees' viewpoint also involvement in the change.

M\&A creates a stress and anxiety in the life of an organization, and during this period, merging companies have to manage the change effectively. By using an effective change in management practices which combine change management techniques with cultural integration tools and techniques, it will enhance the chance of achieving a smooth integration. In which the change itself has to increase the value of a new future organization such as increment of cash flow, expected growth rates increment, a longer growth period, and cost of capital reduction.

To manage this transition change process, the author of this article uses the practices of exemplary 
leadership of James M. Kouzes and Barry Z. Posner. These ten commitments serve as the guide of how leaders get extraordinary things done in organizations and as the structure for what is to follow (Kouzes \& Posner, 1995). The main consideration is that the ten commitments of leadership embedded in this practice can be useful to apply during the transition change process of post-M\&A integration to build employees' engagement and alignment in M\&A changes process. These practices can be a great model for M\&A integration process to build a newly effective system of merging companies in which there exist a balance and high integration between soft factors and hard factors in producing potential useful M\&A change. Those ten commitments of leadership below function as a model to manage the M\&A change transition.

\section{The first practice is challenging the process}

Post-M\&A integration process deals with changing from status quo of companies with their traditional hierarchical structure and companies should work together to create a newly effective common system.

M\&A transaction creates a major disruption of ambiguity, rejection, insecure feeling of employees. Leaders here contribute to building a sense of urgency by pulling employees' attraction with opportunistically rallying on benefit and value creation of $M \& A$ processes such as the international horizon, career perspective, competitiveness, and job security. The sense of urgency can also be built by flattening the priority of the projects. The terms of establishing a sense of urgency above can also be achieved by examining the market and competitive result, and also by identifying and discussing potential crises, or major opportunities (Kotter, 1996). Challenging the process can also be used to build the creative tension of increasing motivation and the urgency level of employees from merging companies by promoting the future benefits of M\&A. The creative tension is an unavoidable gap between one's vision and the current reality where truly creative people use the gap between what they want and what is to generate energy for the change, and they remain true to their vision (Senge, 1990).

Leaders' primary contribution to this process is to change initiator, the leader should move quickly into action by taking and managing risks of M\&A change in their decision. Leaders have to be able to consider the real cost, impact, and benefits of their decision in M\&A change process. By challenging the process practice, it is expected that executive leader of merging companies will buy into M\&A change process and may able to work effectively and fast enough to build a development of a vision and bestshared values to support the strategic plan of M\&A. In this practice, the leader should be deep thinkers who are smart enough to see new possibilities and

Table 1. Ten (10) Commitments of Leadership

\begin{tabular}{|l|l|}
\hline \multicolumn{1}{|c|}{ Practices } & \multicolumn{1}{c|}{ Commitments } \\
\hline Challenging the Process & $\begin{array}{l}\text { 1. Search out challenging opportunities to change, grow, innovate, and improve } \\
\text { 2. Experiment, take risks and learn from the accompanying mistakes }\end{array}$ \\
\hline Inspiring a Shared Vision & $\begin{array}{l}\text { 3. Envisions an uplifting and ennobling future } \\
\text { 4. Enlist others in common visions by appealing to their values, interests, hopes, and dreams }\end{array}$ \\
\hline Enabling Others to Act & $\begin{array}{l}\text { 5. Foster collaboration by promoting cooperative goals and building trust } \\
\text { 6. Strengthen people by giving power away, providing choice, developing competence, } \\
\text { assigning critical tasks, and offering visible support }\end{array}$ \\
\hline Modeling the Way & $\begin{array}{l}\text { 7. Set the example by behaving in ways that are consistent with shared values } \\
\text { 8. Achieve small wins that promote consistent progress and build commitment }\end{array}$ \\
\hline Encouraging the Heart & $\begin{array}{l}\text { 9. Recognize individual contributions to the success of every project } \\
\text { 10. Celebrate team accomplishments regularly }\end{array}$ \\
\hline
\end{tabular}

Source: James M. Kouzes and Barry Z. Posner (1995) 
to conceptualize them (Kanter, 1989).

Based on Ronald A. Heifetz, there are two types of the shifts which require authorities' role with fivedimension social functions (direction, protection, role orientation, and norm maintenance), which are a technical and adaptive situation (Heifetz, 1998). Post-M\&A integration is a type of adaptive work according to the characteristics of social functions where problem definition, solution, and implementation of the process require a learning process. By challenging the process, leaders might be able to identify the adaptive challenge that appears in soft factors for every stakeholder during the integration process and find innovative ways to generate an effective alternative solution for those issues.

This practice may also profound in retraining the mental model as part of the fifth discipline of learning organizations of employees from both companies that see others as an external threat and are being the persistence of change. Mental model governs how we make sense of the world and how we take action in it; mental model limits us to familiar ways of thinking and acting, much to our detriment (Senge, 1990).

\section{The second practice is inspiring a shared vision}

Here shared a vision is beneficial as a foundation of the company's agreement in the way of doing business and value practices of the company. The shared vision also gives the direction of employees towards achieving the strategic objective of M\&A and gives some motivational platform. The leader here should hold forth a vision of the organization's future in compelling ways that ignite the spark needed to build inclusive enterprise (Hesselbein, 2002). In inspiring a shared vision, leaders engage all employees in merging companies to participate in the development of effective vision and new practices values which aim to make employees buy into the vision and reap their support.

Based on the fifth discipline of learning organizations, shared vision creates a commonality that gives a sense of purposes and coherence to all activities the organizations carry out, it vital to provide focus and energy for its employees (Senge, 1990). Vision will be the main outline of a winning strategy objective and be the inspiring strategy of M\&A process. During post-M\&A integration, vision acts as a platform of direction which covers details M\&A objectives and decisions. Vision also helps leaders to bring people to commit to the change and have their willingness to step out their uncertainty fear and give their best effort during the process, and it also gives a fundamental coordination of employees' activities related to the strategic business of M\&A.

Leaders in this practice should also define their jobs in terms of identifying and constantly communicating commonly held values such as vision, shaping such values to enhance performance, and living the commonly held values (Hesselbein, 1996). Effective communication program is a combination of communications goals, flexibility, and feedback where it becomes essential because mostly from $86 \%$ respondents of A.T. Kearney research 1999 said that they failed to communicate their new alliance sufficiently which lead in failure to realize the value of the merger (Deans et.al., 2003).

Leaders here have to be able to promote the expectations of merger and communicate to all stakeholders after the major investment and restructuring decisions are taken, and by effective communication, it is expected that the soft factor issues related to poor communication, extraneous feeling, anxiety, and ambiguity can be resolved. Leaders in this practice should communicate persuasively and truthfully, and also must decide what few pieces of information people really need to know to avoid the high anxiety of people (Hesselbein, 1996).

To inspire the shared vision, leaders should be able to create successful communications within several target groups of M\&A in terms of communicating the new strategic focus, vision, and business targets. The target groups affected by M\&A transaction are employees, CEO, investors, and customers. The major thematic problems are related to the direct impact of their existences in the new company and 
also the continuation of the future contract and relationship. There are several tools that will be useful to solve the communication logjam such as using a personal conversation, media relations such as an intranet, call center, conference calls, and also press guidelines such as press conference, road shows, and company visits.

\section{The third practice is enabling others to act}

The leader should try to engage people in postM\&A integration process by involving employees in establishing the solid structure which will be the future emotional home of an organization under the leader support and supervision. For most companies, the biggest barrier to merger integration is a failure to achieve employees' commitment, and some $37 \%$ respondents of A.T. Kearney research 1999 listed this as their primary challenge, well ahead of obstructive behavior and cultural barriers (Deans et.al., 2003). Leaders should give their support and assistance to make the change project work. This practice is also related to transformational and participative leadership associated with employees' empowerment.

In this practice, leaders should know the importance of trust to increase the interaction level and openness between employees of merging companies towards to a high degree of understanding, engagement, and appreciation of new integrated vision.

In enabling others to act, leader holds on the importance of building merger integration team to work together to set the infrastructure and make detailed decisions of the strategy of M\&A change, based on a new shared vision and practices. PostM\&A integration should embrace the employees, where the team of post-M\&A integration should consist of key executives, managers, and all employees from merging firms to weld together and to mediate conflicting or misperception within them.

Merger integration team will become committing resources of whole companies to propel the M\&A change. The contingency theories in this practice can be applied to enhance team performance. The team forms as team learning which plays a critical role in the success of the newly merged organization. Team learning is a process of aligning a team to avoid wasted energy and to create the results its members want and builds on the disciplines of a shared vision; it involves mastering the practices of dialogue and discussion (Senge, 1990). By enabling others to act within the scope of the merger integration team, it will make employees feel bonded, capable, and committed.

\section{The fourth practice is modeling the way}

The leader including team merger integration should rule out the compelling vision and new strategy in real life to get employees to apply and use them. The board of directors of key executives is structured as a sounding board of change. The new managerial composition will be shown as an identity of the new company and the image of shared values. This is another effective way to communicate the change process to employees. The leader here must behave with integrity where the leader has a clear conviction about values and a steadfastness of purpose in distinguishing between right and wrong, wisdom and foolishness (Hesselbein, 1996).

During post-M\&A integration, leaders should create small winning to show to the employees that the change is valuable and to make employees refocus in forwarding direction. The small wins are also useful to see whether the compelling vision and strategy are effective and viable in the application and also as a temporary estimation of the likelihood of successful integration. Therefore, some corrective actions, improvement methods can be built. The infrastructure and strategy which does not fit with the transformation vision might be adjusted quickly. By modeling the way, leaders can empower, energize, and build longterm commitment of employees in post-M\&A integration around an established common sense of purpose and shared the vision.

The small winnings also help to inject enthusiasm, kindle the spirit by principles consistently espoused by the leader, and gain support from 
employees of the change also block the persistence of M\&As change. Early wins will bring a good sign to the employees that the deal will potentially succeed. However, the company must be carefully assigned their early wins. Some of $61 \%$ of merged companies search for early wins but frequently tread on dangerous territory by turning to job shedding, factory closings, or inward-looking cost moves (Deans et.al., 2003). The early wins might be predicted and analyzed using the due diligence as part of risk management effort where the result of small wins might be seen in the short-term sales report, HR report regarding the work performance, and also in a relationship with other stakeholders such as customer, supplier, and stockholders.

\section{The fifth practice is encouraging the heart}

The leader should motivate employees by visibly cherishing wins and accession of the change. A leader can gain more consolidating gains by recognizing employees' contribution in the change process by giving some motivational rewards such as promotion, compensation benefit, and job security. This will be important during post-M\&A integration regarding the key people retention issue, as a dedicated support, especially to senior executives. Peter F. Drucker set forth the rules for successful acquisitions which one of those, states that well-structured incentives and rewards must be held out to the management of both firms to help make the merger work (Weston, 2001). Anslinger and Copeland identified that successfully acquires who substantially outperformed benchmarks such as S\&P 500 and the Morgan Stanley capital international index by almost $50 \%$ during a recent 10 years period are those who employ the principle of using strong incentives and compensation systems (Weston, 2001).

The author considers the use of exemplary leadership model by James M. Kouzes in managing the transition as part of managing the planned change process over the other models such as fifth disciplines model of learning organizations, adaptive work model from Ronald A. Heifetz, leading change model from John P. Kotter because the model is fully comprehensive approach which covers all important aspect needed in coping with
M\&A change such as articulating the vision, engaging bonds within employees, removing obstacles of information sharing logjam, and building employees' empowerment by promoting the benefit and cherishing the accomplishment.

The author finds that the practices inside the 10 commitments of leadership have some similar points with other models as mentioned above, but the exemplary leadership of James M. Kouzes is simply to apply in real life and can cover the lack of other models related to practices inside them. For example: in the fifth discipline, it misses the practices of how important to model the way by celebrating small wins. Those other models are also a good approach, but their detailed descriptions miss some points of how to manage the transition in post M\&A integration process, and the model that the author uses in this article is considered as a complete and thoughtful basis for a leader to guide the change process and also to guide the employees on achieving the concerned achievements. Throughout the study done in forging this model, it has been discovered that ordinary people who guide others along pioneering journeys follow rather similar paths with the practices inside the model (Kouzes \& Posner, 1995).

And after managing the transition process as a third step of the planned change management, it goes to the last step of managing planned change which is measure result and maintain change which can be employed by some method to accommodate a change measurement from employees such as financial success measures and cultural integration success measures from survey, questioners, and other satisfaction measure.

\section{Organizational Culture}

Organizational culture refers "to a system of shared meaning held by members that distinguish the organizations from other organizations" (Schein, 1985). The culture itself is embedded in employees in several ways namely in a selection process where people who enter the company should match with intangible values of the company; in top management's behavior in which norms and official rules impose the culture; and in socialization where 
employees learn to employ the culture.

Research suggests that there are seven characteristics that, in aggregate, capture the essence of an organization's culture which is innovation and risk-taking, attention to detail, outcome orientation, people orientation, team orientation, aggressiveness, and stability ( $O^{\prime}$ Reilly et.al., 1991). Strong culture tends to increase the level of organizational effectiveness driven by a strong dedication of employees in doing their task.

However, culture can also be a major obstacle for an organization to implement some changes. The strong and arrogant culture will make the change process difficult to implement. M\&A relate with some transformative change and culture incompatibility can be a potential clash within merging companies. The indication of strong differences in values system or culture incompatibility is laying on the differences between seven characteristics of an organizational culture from each merging companies. A strong culture can lead to resistance to change and it might complicate the restructuring process in capturing the value of merging companies. The full M\&A integration is more likely difficult to achieve if merging companies have different broad types of business. Therefore, the deep understanding of merging partners' culture is needed to get some impression of appropriate methods and steps process should be taken in rebuilding a new organization or even in imposing the existing culture to other companies.

A.T. Kearney (1999) have done surveys of 115 transactions around the globe, it has discovered why many mergers are unsuccessful and the cultural differences are being blamed as a reason, those are related to cultural imposition without a further consideration of cultural clash where in some cases is a valid strategy but in others it destroys the value the merger was supposed to create (Deans et.al., 2003). As a conclusion, the major obstacle in the phase of post-M\&A integration is coming from soft factors clash where the cultural clash is part of that.
The term culture clash is defined by its symptoms namely as described below (Carleton \& Lineberry, 2004):

a. Observable differences between the companies involved in a merger about: what is believed; what is important; what is valued; what should be measured; how people should be treated; how people treat one another; how decisions are made; how to manage and supervise; and how to communicate.

b. The disruption that occurs when the way one company conducts its business and treats its people is folded in with another company's way of doing business.

c. Differences of opinion, disagreements, arguments, and different assumptions regarding the internal process of implementing the new business plan and strategy.

d. Perceived differences in organizational beliefs, values, and practices.

e. Perceived differences between the two companies in the degree of formality in style of dress, language, workspace, communication, and so forth.

f. "Winner-Loser" language used by either organization's people.

The soft factors are based on the 7s McKinsey framework which consists of shared values, skills, staff, and style. Those soft factors are correlated with hard factors of $7 \mathrm{~s}$ McKinsey which are structure, strategy, and systems which all together serve as a unifying framework for analyzing and improving the organizational effectiveness which is in this article used to achieve the relation of leadership aspect in M\&A. Unmanageable and clash in soft factors issues may result in a longer time of integration and losing the momentum of the transaction. The leader should be able to identify the culture disparity within merging companies upfront and build a well-managed process to address the differences related to the core objective of M\&A.

Despite other focus of increasing synergies as a realization of hard factors, the major focus in postM\&A integration is related to the managing soft factors issues which remain as the hardest one such 
as the integration of cultures and the coordination of all processes and systems inside the cultures. Companies should determine the type of cultural integration that they want to build around by considering the strength and weakness of each company. Integration strategy and the implementation planning will be based on the type of cultural integration that they choose to pursue.

\section{Cultural Integration Strategy}

There are three different strategies for cultural integration (Picot, 2002):

a. Monoculture strategy where the larger corporation more or less superimposes its corporate culture on a smaller corporation in a kind of 'cultural colonization'.

b. A multicultural strategy where the acquisition retains its own culture, the resulting peaceful coexistence is rated positively and viewed as enrichment.

c. Mixed culture strategy where both corporations merge into one, and the workplace is combined, a new, joint culture develops that is supported by everyone.

\section{DISCUSSIONS}

\section{Henkel's Acquisition of The Dial Corporation}

Based on the case of Dial and Henkel acquisition (Steinbach, 2005), it is evidenced that both companies were successful to do the M\&A transaction and employed the multicultural integration strategy. Each company retained its own culture and its business strengths also overall business. From the illustration above, it is shown that Dial and Henkel saw other business strengths as long-standing and identifiable models which may give a competitive advantage to the new company. The diversity was seen as a potential benefit and enriching opportunities for both companies.

Although both companies retained their culture and their working methodology, the multi-steps of change process were also applied to help in creating the successful integration. The changes were related to how to make a newly merged company combine their positive impact on each other under the new vision, code of conduct, and business strategy. The steps of the change process were based on leadership internalization. The author sees that leadership here played a role in the integration phase in terms of building an effective working relationship and building a mutual understanding between both companies. They tried to employ leadership as a key to bridge their differences; they also imparted some leadership practices of effective communication and knowledge sharing.

The company also tried to create the learning process between them by adopting the key success of each company and employed them to leverage higher growth levels and maintain business position stability. In this cross-border merger, the degree of relatedness between both companies gave a greater virtue for $M \& A$ success.

Both companies treated each other as an equal business partner and built a coherency based on people and knowledge focus. The Dial financial condition made the board of directors realized the importance of making a successful acquisition. Dial was cooperative and willing to be engaged in the whole process. This was shown in the due diligence phase where Dial was openly giving any information which potentially leads to a successful transaction. That was based on the trust between them. Another reason of high participation level during the acquisition process was the consideration of potential mutual benefits, Dial needed Henkel as a financial source which could bring the company through the crisis, and on the other side, Henkel needed Dial as an adjacent source to enter the US market and also to leverage their growth strategy.

In this case the laundry detergent segment, despite pursuing an organic growth, Henkel saw an acquisition as a suitable strategy to build up its product category and strengthen its home and personal care business. The improvement after M\&A transaction can be seen in higher US market share position for Henkel in its product category and also in transfer of knowledge of product development for Dial. 


\section{BP Amoco}

The author also shows the application of monoculture strategy or cultural imposition in the case of BP Amoco. The case example is based on Lit search (Lit Search, 1999): A merger between British Petroleum (BP) and American Oil Company (Amoco) (also Atlantic Richfield Company (ARCO) and Burmah Castrol). This was a multibillion-dollar transaction in 1998-2000 aimed to create a new single and global company having \$200 billion market capitalization. The vision behind the acquisition was to be a global player, to enter retail markets in the world, and fill the strategic gap in natural gas and the Far East. The key success factors of this M\&A transaction were BP's ability to move quickly in capturing the near-term synergies and creating common values and processes.

The improvement after M\&A can be seen in 20\% cost cutting of the combined BP-Amoco cost base. Another improvement was that in within 100 days of closing the Amoco deal, BP was successful in completing the cost-cutting projects including some 10.000 layoffs and built the organizational structure especially in filling all the top management jobs. During that period, the success of transaction can be seen in rising of BP-Amoco's stock price by nearly $11 \%$. In the change transition, the leaders consistently and visibly led the change and cherished the process. The change transition was facilitated by open communications to all stakeholders.

The integration strategy taken by the leader in this M\&A transaction was by imposing BP's structure and management style on the new company. That strategy led to the resignation of some key senior executives at Amoco. However, on the other side there exist the high performing results of the merger where BP achieved the projected $\$ 2$ billion in cost savings within the first year. In a year ahead of schedule, there was a $19 \%$ increase in second quarter 1999 pre-exceptional profits to \$1.36bn. Those improvements presented a definitive counterpoint to the perception that M\&A activity destroys shareholder value.

Another winning approach which employed as a strategy to manage the change transition of merger BP-Amoco was that each company gained an international experience of cross-border M\&A prior to BP's acquisition. BP has integrated with Standard Oil of Ohio, while Amoco learned valuable lessons with its purchase of Canada's Dome Petroleum (Deans et.al., 2003).

Based on this case example, it is obvious that the monoculture integration strategy or cultural imposition can also lead to a value creation. That is because strong leadership was applied in the process. As mentioned in the explanation of the type of cultural integration, the cultural imposition may lead to some value destruction which in this case can be seen in higher unwanted turnover at Amoco. However, on the other hand, the leader of BP tried to minimize the disruption caused by cultural imposition by instilling leadership as a basis of M\&A change in the area of communication, leader's support, attribute shared value, and creating a feasible shared vision. The leader also effectively communicated the vision of the change, nurturing them via the vision, and giving an appropriate support to the employees during the transition process.

From two examples that have been elucidated of Dial Henkel, and BP Amoco, where each one represented the type of cultural integration strategy of multicultural, and mixed culture, it is shown that successful integration requires leadership as a foundation to build a solid execution of post M\&A integration projects in how they planned, communicated and delivered the objectives of the projects. The case examples also invigorate the author's suggestion of the important role of leadership in M\&A situations. Those success stories also become one of the author's considerations in determining the critical success factor of M\&A and the conclusion of relation and linkage between leadership and M\&A.

\section{Conclusion}

One of the key success factors for successful Merger and Acquisition is the development and execution of an effective post-M\&A integration that is described below: 
- Good integration planning process which represents a fast and quick transition process.

- Clear M\&A objectives covering financial and others non-financial goals and exact determination of prioritization of those objectives.

- Realistic and objective assessment of the real valuation of the company including synergy benefit and cost of integration

- Establishment of an effective post-M\&A integration structure and synergy realization process

- A smooth execution of integration using a topdown approach and a technology system for knowledge sharing system, reporting requirements, and integrated communication system

- Clarity of future contractual structure and future work relationship with an external party such as supplier distributor, and so forth

It could be proposed that leadership and effective post-M\&A integration are becoming the key success factors of overall M\&A transaction. The author concludes that both key factors are related and complement each other, and there are a relation and linkage between them in which bold and strong leadership is needed and used to create effective post M\&A integration Strong leadership should be implemented early on at the beginning of $M \& A$ process where the precise implementation can be formed in HR due diligence. Leadership will help to ensure the preparation including the processes, methodology, and management behavior, are ready to generate the planned integration synergies.

The author also concludes for the relation and linkage between leadership and M\&A that leadership should become the main consideration role after closing phase; leadership will help to mitigate the risk of dual organization and management and to keep the business of both companies performing well during the transition period from old business framework to new reengineered framework.

\section{REFEREN CES}

Carleton, J. R., \& Lineberry, C. (2004). Achieving post-merger success: A stakeholder's guide to cultural due diligence, assessment, and integration. John Wiley \& Sons.

Deans, G. K., Kroeger, F., \& Zeisel, S. (2003). Winning the Merger Endgame, a Playbook for Profiting from Industry Consolidation. New York: McGraw-Hill Professional Publishing.

Harvey, D., \& Donald R.B. (2000). An Experiential Approach to Organization Development (Paperback). NJ: Prentice Hall.

Heifetz, R.A. (1998). Leadership Without Easy Answers (Hardcover). Cambridge, Massachusetts, London, England: Belknap Press the Belknap Press of Harvard University Press.

Hesselbein, F. (1996).The Leader of the Future. San Fransisco: Jossey-Bass.

Hesselbein, F. (2002). Hesselbein on leadership. San Fransisco: Jossey-Bass.

Hunsaker, P.L. (2005). Management, A Skills Approach. NJ: Prentice Hall.

Hunt, P.A. (2004). Structuring Mergers \& Acquisitions: A Guide to Creating Shareholder Value. New York: Aspen Publishers.

Kanter, R.M. (1989). When Giants Learn to Dance. London: Simon \& Schuster/ Touchstone.

Kanter, R.M. (1990). World Class: Thriving Locally in the Global Economy (Hardcover). London: Simon \& Schuster/ Touchstone. 
Kotter, J.P. (1996). Leading Change (Hardcover). Boston: Harvard Business School Press.

Kouzes, J.M., and Barry Z.P. (1995). The Leadership Challenge, 4th Edition (Hardcover). San Fransisco: JosseyBass.

Lit search. (1999). BP-Amoco's Result a Tribute to M \& A Success. In: The Financial News.

Likert, R. (1967). The human organization: Its Management and Value. New York: McGraw-Hill.

Lucks, K. (2005). Transatlantic Mergers and Acquisitions: Opportunities and Pitfalls in German-American Partnerships. Munich:Wiley.

O'Reilly III, C. A., Chatman, J., \& Caldwell, D. F. (1991). People and organizational culture: A profile comparison approach to assessing person-organization fit. Academy of management journal, 34(3), 487-516.

Picot, G. (2002). Economic and business law parameters for the planning of mergers and acquisitions. Handbook of international mergers and acquisitions: Preparation, implementation and integration, 328.New York: Palgrave Macmillan.

Rasiel, E. M., \&Friga, P. N. (2002). The Mc Kingey mind: understanding and implementing the problem solving tools and management techniques of the world's top strategic consulting firm. New York: Mc GrawHill.

Schein, E. H. (2010). Organizational culture and leadership(Vol. 2). John Wiley \& Sons.

Senge, P.M. (1990). The Fifth Discipline (Paperback). London: Century Business.

Steinbach, Lothar, Steve, B., and Helmut B.B. (2005). Henkel's acquisition of the Dial Corporation, Scottsdale, USA. Transatlantic Mergers And Acquisitions: Opportunities And Pitfalls in German-American Partnerships. Munich:Wiley.

Waterman, R. H., Peters, T. J. (1988). In search of excellence: Lessons from America's best-run companies. New York: Grand Central Publishing.

Weston, J. F., \& Weaver, S. C. (2004). Mergers \& Acquisitions. McGraw-Hill Professional. 